\title{
Personal and contextual antecedents of achievement goals: Their direct and indirect relations to students' learning strategies
}

\author{
Aikaterini Michou $^{\mathrm{a}, *}$, Athanasios Mouratidis ${ }^{\mathrm{b}}$, Willy Lens ${ }^{\mathrm{b}}$, Maarten Vansteenkiste ${ }^{\mathrm{c}, 1}$ \\ a Bilkent University, Graduate School of Education, Main Campus-G Building, 06800, Bilkent, Ankara, Turkey \\ b University of Leuven, Department of Psychology, Tiensestraat 102, B-3000 Leuven, Belgium \\ c Ghent University, Department of Psychology, H. Dunantlaan 2, 9000 Gent, Belgium
}

\section{A R T I C L E I N F O}

\section{Article history:}

Received 3 November 2011

Received in revised form 14 July 2012

Accepted 6 September 2012

\section{Keywords:}

Achievement goals

Classroom goal structure

Need for achievement

Fear of failure

Learning strategies

\begin{abstract}
A B S T R A C T
In this correlational research, we investigated to what extent achievement goals, in conjunction with need for achievement and fear of failure as well as perceived classroom goal structures, are related to learning strategies among upper elementary school students. After taking into account students' tendency to respond in a socially desirable way, we found, through path analysis, that mastery-approach goals partially mediated the relation of need for achievement and perceived mastery goal structures to learning strategies. These findings are discussed within the hierarchical model framework proposed by Elliot (1999). They suggest that the simultaneous examination of personal and contextual antecedents of achievement goals can enhance our understanding of the processes underlying achievement motivation and its outcomes.
\end{abstract}

(c) 2012 Elsevier Inc. All rights reserved.

\section{Introduction}

Based on the hierarchical model of achievement motivation (Elliot, 1999), past research has indicated that achievement goals can account for the relation between either personal or contextual antecedents and motivational outcomes (e.g., Bartels \& Magun-Jackson, 2009; Church, Elliot, \& Gable, 2001; Diseth \& Kobbeltvedt, 2010). However, less is known about the mediating role of achievement goals when both sets of antecedents are simultaneously considered in the prediction of motivational outcomes such as learning strategies.

In this research, we used a sample of elementary school students to investigate the patterns of relations among achievement goals, personal (i.e., need for achievement and fear of failure) and contextual (i.e., perceived classroom goal structures) antecedents, and learning strategies. When investigating these interrelationships, we controlled for students' social desirability because as the pursuit of certain goals (such as mastery goals) are more valued, students may report a stronger endorsement of such goals to meet teachers' expectations (Darnon, Dompnier, Delmas, Pulfrey, \& Butera, 2009). As for achievement goals, we conceived them as pure aims and thus defined them distinctly from any fear of failure or any desire to show off competence to others (Elliot, 2005). With respect to learning strategies, we focused on three aspects - critical

\footnotetext{
* Corresponding author at: Bilkent University, Graduate School of Education, Main Campus-G Building, 06800, Bilkent, Ankara, Turkey. Tel.: +90312 2903039.

E-mail addresses: aliki.michou@bilkent.edu.tr (A. Michou),

Thanasis.Mouratidis@psy.kuleuven.be (A. Mouratidis), Willy.Lens@psy.kuleuven.be

(W. Lens), Maarten.Vansteenkiste@ugent.be (M. Vansteenkiste).

Tel.: + 3292646413
}

thinking, metacognitive self-regulation, and effort regulation - that we consider to represent students' high quality intentional strivings toward learning facilitation (Weinstein \& Mayer, 1986).

\subsection{Achievement goals and motivational outcomes}

Achievement goals are defined as cognitive-motivational purposes for engagement in a particular task where competence is at stake (Dweck \& Leggett, 1988). Students who use self-referenced or task-referenced standards (i.e., mastery) for defining their competence and orient themselves toward success (i.e., approach) are said to endorse mastery-approach goals. When endorsing masteryapproach goals, students focus on self-improving, understanding, and learning. Students who use other-referenced standards for defining their competence and orient themselves toward success are considered to adopt performance-approach goals. These students focus on outperforming others. In contrast, students using other-referenced standards but orienting themselves away from failure (i.e., avoidance) are assumed to endorse performance-avoidance goals; they focus on avoiding being worse than others ${ }^{2}$ (Elliot \& McGregor, 2001). Conceiving

\footnotetext{
2 There is also a possibility that individuals use self-referenced or task-referenced standards and orient themselves away from failure, when for instance they strive to avoid occasions where learning or acquired skills are at stake. In this case individuals are assumed to endorse a mastery-avoidance goal (Elliot \& McGregor, 2001). However, because mastery-avoidance goals seem to be more salient in elderly people than in younger population (Elliot, 1999; Ciani \& Sheldon, 2010), we decided to disregard mastery-avoidance goals in our research.
} 
achievement goals according to how competence is defined and valued implies that achievement goals are conceptualized as pure aims, and are thus distinct from any reason or motive (e.g., fear of failure, challenge seeking, or need for social approval) underlying their pursuit. This recent approach lends conceptual clarity in the Achievement Goal Theory as the literature review has shown that the "same" achievement goal is in some cases conceptualized and operationalized differently, yet produced contradictory results (Hulleman, Schrager, Bodmann, \& Harackiewicz, 2010).

Past research has indicated that mastery-approach goals are linked with adaptive learning patterns such as increased self-regulated learning (Pintrich, 2000) and cognitive and metacognitive strategies (Bartels \& Magun-Jackson, 2009; Harackiewicz, Durik, Barron, Linnenbrink-Garcia, \& Tauer, 2008). Performance-avoidance goals have been linked with less adaptive learning strategies (Diseth \& Kobbeltvedt, 2010), including self-handicapping, and weak self-regulatory skills (Senko, Durik, \& Harackiewicz, 2008). Performance-approach goals have been associated with both positive and negative outcomes. While they have been found to be positively related to intrinsic motivation, they were also positively related to surface processing or not related to deep processing and self-regulated learning (see Elliot \& Moller, 2003).

Notably, although achievement goals have been extensively studied within the framework of the hierarchical model of achievement motivation (Elliot \& Church, 1997), only few studies (e.g., Elliot \& Church, 1997, Elliot \& Murayama, 2008) have examined how achievement goals, in concert with their potential antecedents, are linked with motivational outcomes. It is, however, critical to examine achievement goals along with multiple antecedents, such as achievement motives and the perceived classroom environment, as the endorsement of achievement goals can be influenced by multiple sources (Elliot, 1999).

\subsection{The hierarchical model of achievement motivation}

In the hierarchical model of achievement motivation it has been proposed that the endorsement of achievement goals may be influenced, among others, by competence-based constructs (e.g., achievement motives), and perceived environmental factors (e.g., the motivational environment) (Elliot, 1999). Despite the large number of possible antecedents of achievement goals, the most widely studied antecedents have been the achievement motives (Atkinson, 1957): the need for achievement or the motive to succeed and the fear of failure or the motive to avoid failure in achievement tasks.

Past research has indicated that mastery-approach goals are instigated by the need for achievement, performance-avoidance goals by the fear of failure, and performance-approach goals by both the need for achievement and fear of failure (Elliot \& Church, 1997; Elliot \& Harackiewicz, 1996). When studying the sequence of relations among achievement motives, achievement goals, and outcomes, it has been shown that the need for achievement is related to metacognitive strategies either directly (Chen, Wu, Kee, Lin, \& Shui, 2009; Diseth \& Kobbeltvedt, 2010) or indirectly through mastery-approach goals (Bartels \& Magun-Jackson, 2009).

Another set of antecedents of achievement goals that has been investigated within the hierarchical model of achievement motivation concerns contextual factors. It has been proposed that encouraged goal-structures within classrooms may influence students' adoption of different achievement goals (Ames, 1992, Maehr \& Midgley, 1996). Specifically, mastery goal structures, which represent learning environments where teachers, through their instructional practices, encourage students' strivings for mastery, understanding and self-improvement, are presumed to facilitate the endorsement of mastery-approach goals. In contrast, performance-approach goal structures, which reflect a classroom climate where competition among students is highlighted, are thought to promote performance-approach goals, whereas performance-avoidance goal structures which refer to learning environments in which teachers emphasize the avoidance of doing worse than others (Church et al., 2001) are considered to favor the endorsement of performance-avoidance goals.

Apart from investigating the indirect effects of classroom goal structures on outcomes through personal achievement goals, past research has also tested, next to achievement goals, the direct, independent effects of classroom goal structures on motivational outcomes (Murayama \& Elliot, 2009). Both lines of research have indicated that students' perceptions of mastery goal structures are associated with endorsing mastery goals, deep-level processing strategies, intrinsic motivation, and higher academic achievement (Lau \& Nie, 2008; Miki \& Yamauchi, 2005; Murayama \& Elliot, 2009). On the other hand, it was shown that perceived performance goal structures have been associated with surface processing (Miki \& Yamauchi, 2005), self handicapping strategies (Miki \& Yamauchi, 2005; Urdan, 2004), and decreased intrinsic motivation (Murayama \& Elliot, 2009). In our study, we therefore tested whether next to the motivational dispositions of need for achievement and fear of failure, perceived classroom structures are related to learning strategies, and to what extent achievement goals mediate this relationship.

\subsection{The present study}

In the present study we aimed to add to the existing knowledge about achievement goal research in four ways. First, we tested the hierarchical model of achievement motivation by investigating to what extent personal and contextual antecedents of achievement goals, when considered simultaneously, yield an independent contribution to learning strategies and whether these relations are mediated by achievement goals. Second, we examined these patterns of relations by assessing achievement goals as pure aims. Third, given the dearth of studies in younger student populations, we tested the hierarchical model of achievement motivation in a sample of elementary school students rather than college students. Finally, we controlled for students' likely socially desirable responses as previous research has indicated that replying to questions regarding fear of failure (see Conroy, 2001) or personal achievement goals (see Darnon et al., 2009) may elicit socially desirable responses.

Given that we investigated the hierarchical model of achievement motivation and that we assessed achievement goals as pure aims, we hypothesized that achievement goals would partially mediate the relation of achievement motives and classroom goal structures to learning strategies. We anticipated both direct and indirect relations of the four antecedents (i.e., need for achievement, fear of failure, perceived mastery-approach and perceived performance-approach goals structures) to learning strategies. In this broader perspective, we formulated the following hypotheses (Fig. 1).

Hypothesis 1. With respect to the indirect relations, we expected that need for achievement, as an approach dispositional characteristic, would be positively linked to mastery-approach and performanceapproach goals (Hypothesis 1a), whereas fear of failure, as an inhibitory tendency (Atkinson, 1957), would be positively linked to performanceavoidance goals (Hypothesis $1 \mathrm{~b}$ ). Despite the inhibitory nature of fear of failure, we also considered the possibility that fear of failure would be positively related to performance-approach goals (Hypothesis 1c) as outperforming others could be conceived by elementary students as a means to avoid failure (Elliot \& Church, 1997).

Hypothesis 2. In parallel, we expected a positive relation between perceived mastery goal structures and mastery-approach goals as both of them focus on self-improvement and understanding (Hypothesis 2a). Similarly, we anticipated a positive relation between perceived performance-approach goal structures and performance-approach goals as well as between perceived performance-avoidance goal structures and performance-avoidance goals as both of them focus on competition (Hypothesis $2 b$ ). 


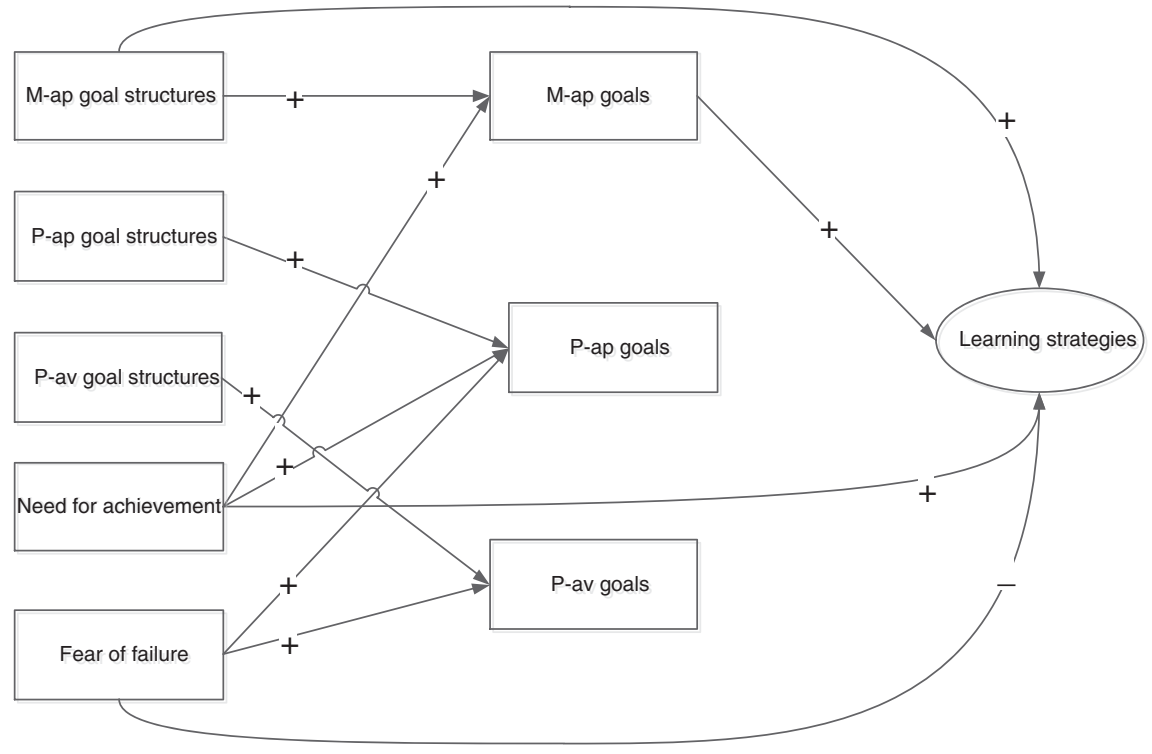

Fig. 1. The hypothesized model of the study.

Hypothesis 3. In sequence, we expected mastery-approach goals to be a positive predictor of adaptive learning strategies because endorsing mastery-approach goals implies a focus on the learning process and hence on the use of adaptive learning strategies. In contrast, once we would assess performance-approach and performance-avoidance goals distinct from any desire to demonstrate competence or to avoid demonstrating incompetence respectively, we had no firm hypothesis about their relation to learning strategies.

Hypothesis 4. With respect to the direct relations between antecedents and learning strategies, we expected, similar to previous studies (e.g., Bartels \& Magun-Jackson, 2009; Diseth \& Kobbeltvedt, 2010) that need for achievement and fear of failure will be a positive and a negative predictor, respectively, of learning strategies (Hypothesis 4a). This is because the need for achievement, as an approach tendency, prompts toward effective acting like self-regulated learning, whereas fear of failure, as an inhibitor, intercepts effective learning. Similarly, because the motivational climate of the classroom that promotes, through the respective instruction practices, understanding and improving is more likely to facilitate students' use of effective learning strategies compared to the classroom that emphasizes competition (Miki \& Yamauchi, 2005; Urdan, 2004), we anticipated only perceived mastery-approach goal structures to be direct positive predictors of learning strategies (Hypothesis $4 \mathrm{~b}$ ). Furthermore, we expected that these associations would be observed over and above students' tendency to provide socially desirable responses.

\section{Method}

\subsection{Participants}

One hundred and eighty-nine (48.1\% males; two students omitted reporting their gender) fifth- $(n=84)$ and sixth-grade $(n=105)$ students $\left(M_{\mathrm{age}}=11.55, S D=0.66\right)$ belonging to 11 classes from two public elementary schools in Greece participated in this study. The two schools were located in two districts of average socioeconomic status in the metropolitan area of Athens, Greece. According to the Greek educational system, elementary schools have six grades and in each class students have one teacher for most of the subject matter (except for physical education, foreign language, and music). Permission to conduct this research was granted first from the Greek Ministry of Education and then from the principals and the board of teachers of schools. In addition, an informed consent from parents was obtained.

Students were informed that the purpose of the study was to get their opinion about daily school life and that there were no right or wrong answers. Also, students were assured about the confidentiality of their responses and it was made explicitly clear to them that they could quit the session whenever they decided to do so. All students agreed to participate. They filled in the following questionnaires all of which were independently translated by two experts in the field and adjusted according to the procedures proposed by Hambleton (1994).

\subsection{Materials}

\subsubsection{Social desirability}

A short form of the Marlowe-Crowne social desirability scale (Thompson \& Phua, 2005) was used to assess students' propensity to provide socially desirable answers. Ten items (e.g., "You never resent being asked to return a favor") were worded in a true/false format $(0=$ non-socially desirable response; $1=$ socially desirable response). The internal consistency of this scale upon the exclusion of one item was $\alpha=.60$.

\subsubsection{Achievement motivation}

A short version of the achievement motivation scale (AMS) (Lang \& Fries, 2006) was employed to assess on a 5-point Likert-type scale $(1=$ Not at all true of me; $5=$ Very true of me) need for achievement (5 items; e.g., "I like situations, in which I can find out how capable I am"; $\alpha=.75$ ) and fear of failure (5 items; e.g., "I feel uneasy to do something if I am not sure of succeeding"; $\alpha=.71$ ). Previous research has shown that students of the age of our participants can comprehend questions regarding their own motives (Bjørnebekk \& Diseth, 2010). A confirmatory factor analysis (CFA) for a two-latent factor model showed an almost perfect fit (S-B $\chi^{2}[34, N=179]=35.02$, $p=.42, \mathrm{CFI}=.996, \mathrm{SRMR}=.048, \mathrm{RMSEA}=.013$ [90\% CI: .000-.056]), providing evidence of the factorial validity of the used scale.

\subsubsection{Achievement goals}

The revised Achievement Goal Questionnaire (AGQ-R; Elliot \& Murayama, 2008) was recruited to assess on a 5-point Likert-type scale ranging from 1 (Not at all true of me) to 5 (Very true of me) pupils' mastery-approach goals ( 3 items; e.g., "My aim is to completely master 
the material presented in this class"; $\alpha=.65)$, performance-approach goals ( 3 items; e.g., "My aim is to perform well relative to other students"; $\alpha=.84$ ), and performance-avoidance goals ( 3 items; e.g., "My aim is to avoid doing worse than other students"; $\alpha=.64$ ). Similar scales have been proved to be suitable for population samples of that age (Bjørnebekk \& Diseth, 2010; Bong, 2009). CFA for a three-factor solution yielded an acceptable fit $(\mathrm{CFI}=.944, \mathrm{SRMR}=.056, \mathrm{RMSEA}=.072$ [90\% CI: .038-.104]) although the model-based covariance matrix failed to reproduce the data covariance matrix: S-B $\chi^{2}(24 N=169)=44.76$, $p<.01$.

\subsubsection{Perceived classroom environment}

Similar to previous studies with elementary school students (e.g., Tapola \& Niemivirta, 2008), a set of items from the Patterns of Adaptive Learning Strategies (PALS; Midgley et al., 2000; Urdan, 2004) was used to gage elementary school students' perceptions of the mastery oriented (4 items; e.g., "In our class, it's OK to make mistakes as long as you are learning"; $\alpha=.65)$, performance-approach oriented ( 5 items; e.g., "In our class, there is a lot of competition among students"; $\alpha=$.67), or performance-avoidance oriented ( 4 items; e.g., "In this class, students don't want to look like the work is hard for them"; $\alpha=.62$ ) classroom environments. All the items were anchored on a 5-point Likert-type scale $(1=$ Not at all true of me; $5=$ Very true of me). CFA resulted in acceptable fit S-B $\chi^{2}(62, N=165)=73.35, p<.15$, $\mathrm{CFI}=.962, \mathrm{SRMR}=.058, \mathrm{RMSEA}=.033(90 \% \mathrm{CI}: .000-.060)$, but the performance-approach and performance-avoidance goal structures latent factors were highly correlated $(r=.78 p<.01)$. This high correlation cast some doubt on whether in the present research the performance-approach and performance-avoidance goal structures could indeed be discriminated in the pupils' minds. In light of this finding, and after taking into account that previous studies (e.g., Kaplan, Gheen, \& Midgley, 2002; Murayama \& Elliot, 2009) which have similarly failed to show a meaningful difference between perceived performanceapproach and performance-avoidance goal structures, we decided to retain only performance-approach goal structures as they seem more easily understood by students of that age.

\subsubsection{Motivated learning strategies}

Similarly to previous studies that used students of that age (Metallidou \& Vlachou, 2010) three aspects of fifth and sixth grade students' learning strategies as outlined by Pintrich and De Groot (1990) were assessed. Specifically, students' were asked to report on a 5-point Likert-type scale ranging from 1 (Not at all true of me) to 5 (Very true of me) to what extent they (a) recruit critical thinking ( 5 items; e.g., "I often find myself questioning things I hear or read in this course to decide if I find them convincing"; $\alpha=.69$ ), (b) employ metacognitive self-regulation ( 5 items; e.g., "When I become confused about something I'm reading for my class, I go back and try to figure it out"; $\alpha=.61$ ), and (c) regulate their effort in an efficient way (3 items; e.g., "I work hard to do well in this class even if I don't like what we are doing"; $\alpha=.65)$. A CFA for a model where the three latent factors of critical thinking, effort regulation, and metacognitive self-regulation would load on a learning strategies higher-order latent factor showed an acceptable fit S-B $\chi^{2}(64, N=167)=86.19, p<.01, \mathrm{CFI}=.924$, SRMR $=$ .073 , RMSEA $=.065$ (90\% CI: .043-.085). The Cronbach alpha for the whole scale was $\alpha=.78$. Eventually, individual scores for learning strategies were computed by aggregating the scores for critical thinking, metacognitive self-regulation and effort regulation.

\section{Results}

\subsection{Preliminary analyses}

The means, standards deviations and bivariate correlations among the variables are presented in Tables 1 and 2, respectively. Preliminary analyses showed significant differences due to gender (Wilk's $\Lambda=$
$.820, F[9,167]=4.06, p<.01$, multivariate $\left.\eta^{2}=.18\right)$ and grade-level (Wilk's $\Lambda=.843, F[9,169]=3.50, p<.01$, multivariate $\eta^{2}=.16$ ). Follow-up ANOVA (see Table 1 ) with the alpha level adjusted according to the Bonferroni correction showed that females reported higher levels of need for achievement, fear of failure, and learning strategies than males. Also, fifth-grade students indicated stronger endorsement of performance-approach and performance-avoidance goals than sixthgrade students. Consequently gender and grade were included as covariates in our subsequent analyses.

\subsection{Main analyses}

Because of the small number of classes $(n=11)$ we avoided employing multilevel analysis (Maas \& Hox, 2005), although inspection of the intraclass correlation coefficients (ICC's: .00-.16) of the measured variables suggested some shared variance due to classroom effects. Likewise, due to the relatively small sample size, we tested our hypotheses through path instead of full structural model with all the constructs being represented by the mean scores of their measured variables (except learning strategies which we defined by means of metacognitive self-regulation, effort regulation, and critical thinking). All the hypothesized paths were significant except the paths from fear of failure, performance-approach and performance-avoidance goals to learning strategies which were therefore dropped from the revised model. The final model (see Fig. 2) yielded acceptable fit: $\mathrm{S}-\mathrm{B} \chi^{2}(37, N=$ $176)=65.01, p<.01, \mathrm{CFI}=.933, \mathrm{SRMR}=.069, \mathrm{RMSEA}=.066(90 \%-\mathrm{CI}$ : $.038-.091)$.

In support of our Hypotheses 1a, 1b and 1c, need for achievement was positively related to mastery-approach and performance-approach goals $(\beta=.23, p<.01 ; \beta=.13, p<.05$, respectively). In contrast, fear of failure was positively related to performance-avoidance goals $(\beta=.16$, $p<.01)$ and, although marginally, to performance-approach goals $(\beta=$ $.15, p=.05)$. These findings suggest that the more students enter an achievement situation with the motive to succeed, the more they focus on mastery striving and self-improving and the more they focus on outperforming others (albeit to a lesser extent). The results also suggest that the more students are afraid of failing, the more they focus on competition and on avoiding performing worse than others.

Concerning the contextual antecedents and in line with Hypotheses $2 \mathrm{a}$ and $2 \mathrm{~b}$, perceived mastery-approach goal structures were positively related to mastery-approach goals $(\beta=.20, p<.01)$ and performance-approach goal structures to performance-approach goals $(\beta=.31, p<.01)$. These results imply that the motivational environments which make the mastery versus competitive goals salient may facilitate the adoption of the corresponding goals.

In sequence, and in line with Hypothesis 3, the path between mastery-approach goals (but not between either performance-approach or performance-avoidance goals) and learning strategies $(\beta=.22$, $p<.01$ ) suggests that when all the three achievement goals are jointly considered, only mastery goals are associated with adaptive learning strategies. A test of indirect effects showed that need for achievement and perceived mastery goal structure were significantly related to learning strategies by means of mastery-approach goals $(\beta=.05, z=2.08$, $p<.05$ and $\beta=.04, z=1.99, p<.05$, respectively).

Finally, Hypotheses $4 \mathrm{a}$ and $4 \mathrm{~b}$ were partly supported as perceived mastery-approach goal structures and need for achievement were directly and positively related to learning strategies $(\beta=.17, p<.05$ and $\beta=.43, p<.01$, respectively). These findings denote that the adaptive motivational dispositions and environmental-based variables can directly predict some of the variance of learning strategies among elementary school students.

\section{Discussion}

In the present research we tested the hierarchical model of achievement motivation in a sample of elementary school students. Having 
Table 1

Means and standard deviations of the measured variables of the study for the total sample, males and females, and fifth- and sixth-graders.

\begin{tabular}{|c|c|c|c|c|c|c|c|c|c|c|c|c|c|c|}
\hline \multirow[t]{4}{*}{ Variables } & \multicolumn{2}{|c|}{ Full sample } & \multicolumn{6}{|c|}{ Gender differences } & \multicolumn{6}{|c|}{ Grade-level differences } \\
\hline & \multirow[b]{3}{*}{$M$} & \multirow[b]{3}{*}{$(S D)$} & \multirow{2}{*}{\multicolumn{2}{|c|}{$\frac{\text { Males }}{(n=85)}$}} & \multirow{2}{*}{\multicolumn{2}{|c|}{$\frac{\text { Females }}{(n=92)}$}} & \multirow{3}{*}{$F(1,175)$} & \multirow{3}{*}{$\eta^{2}$} & \multirow{2}{*}{\multicolumn{2}{|c|}{$\frac{5 \text { th-grade }}{(n=80)}$}} & \multirow{2}{*}{\multicolumn{2}{|c|}{$\frac{6 \text {-th grade }}{(n=99)}$}} & \multirow{3}{*}{$F(1,177)$} & \multirow{3}{*}{$\eta^{2}$} \\
\hline & & & & & & & & & & & & & & \\
\hline & & & $M$ & $(S D)$ & $M$ & $(S D)$ & & & $M$ & $(S D)$ & $M$ & $(S D)$ & & \\
\hline 1. Social desirability & 4.93 & $(2.00)$ & 5.20 & $(1.95)$ & 4.68 & $(2.05)$ & 2.93 & .02 & 5.00 & (1.99) & 4.90 & $(2.03)$ & 0.11 & .00 \\
\hline 2. Need for achieve & 4.08 & $(0.62)$ & 3.91 & $(0.68)$ & 4.25 & $(0.52)$ & $13.96^{*}$ & .07 & 4.18 & $(0.62)$ & 4.00 & $(0.61)$ & 3.46 & .02 \\
\hline 3. Fear of failure & 3.42 & $(0.77)$ & 3.24 & $(0.66)$ & 3.59 & $(0.83)$ & $9.22^{*}$ & .05 & 3.56 & $(0.76)$ & 3.32 & $(0.77)$ & 4.19 & .02 \\
\hline 4. Mastery GS & 4.18 & $(0.67)$ & 4.13 & $(0.67)$ & 4.22 & $(0.63)$ & 0.90 & .01 & 4.31 & $(0.63)$ & 4.07 & $(0.65)$ & 6.05 & .03 \\
\hline 5. P-ap GS & 3.36 & $(0.78)$ & 3.32 & $(0.83)$ & 3.38 & $(0.75)$ & 0.24 & .00 & 3.47 & $(0.82)$ & 3.25 & $(0.75)$ & 3.49 & .02 \\
\hline 6. M-ap goals & 4.55 & $(0.59)$ & 4.49 & $(0.60)$ & 4.61 & $(0.54)$ & 1.91 & .01 & 4.57 & $(0.55)$ & 4.55 & $(0.58)$ & 0.12 & .00 \\
\hline 7. P-ap goals & 3.80 & $(1.05)$ & 3.76 & $(1.10)$ & 3.80 & $(1.03)$ & 0.05 & .00 & 4.19 & $(0.76)$ & 3.44 & $(1.14)$ & $24.76^{*}$ & .12 \\
\hline 8. P-av goals & 3.77 & $(0.96)$ & 3.61 & $(1.07)$ & 3.94 & $(0.85)$ & 5.26 & .03 & 4.03 & $(0.87)$ & 3.58 & $(1.00)$ & 9.93* & .05 \\
\hline 9. Learning strategies & 3.64 & $(0.60)$ & 3.50 & $(0.62)$ & 3.78 & $(0.56)$ & 9.98* & .05 & 3.76 & $(0.58)$ & 3.55 & $(0.61)$ & 5.45 & .03 \\
\hline
\end{tabular}

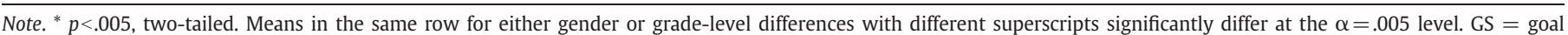
structures; M-ap = Mastery-approach; P-ap = Performance-approach; P-av = Performance-avoidance.

assessed achievement goals as pure aims, we investigated to what extent personal and contextual antecedents of achievement goals are related to learning strategies either directly or indirectly through achievement goals. Below, we discuss the three parts of the examined model, that is, (a) the relation between antecedents and achievement goals, (b) the relation between achievement goals and learning strategies, and (c) the explanatory role of achievement goals in the relation between personal and contextual antecedents and learning strategies.

\subsection{The relation between antecedents and achievement goals}

With regard to the personal antecedents, our findings showed, in line with the hierarchical model (Elliot, 1999), that mastery-approach and performance-avoidance goals were uniquely (and positively) predicted by need for achievement and fear of failure, respectively, and that performance-approach goals were positively predicted by both the need for achievement and fear of failure. It seems that elementary students' tendency toward achievement facilitates the adoption of approach achievement goals (i.e., mastery-approach and performanceapproach goals), whereas their tendency to avoid failure facilitates the adoption of competitive (i.e., performance-approach and performanceavoidance) goals. Although Atkinson (1957) considered fear of failure as a pure inhibitory motive, it seems that, young children who are inclined to eschew failure may as well strive for normative success, presumably because outperforming others subdues their failure concerns.

Because few studies have simultaneously considered the role of multiple antecedents, we examined whether next to personal antecedents, contextual ones would yield an independent association with achievement goals. This appears to be the case. Specifically, perceived classroom goal structures that focus on improving and understanding the learning material (i.e., perceived mastery goal structures) were uniquely (and positively) related to mastery-approach goals, whereas perceived classroom goal structures that focus on competition (i.e., perceived performance-approach goal structures) were uniquely (and positively) related to performance-approach goals.

\subsection{The relation between achievement goals and learning strategies}

In line with the abundant evidence showing the adaptive nature of mastery-approach goals, we found these goals to predict learning strategies over and above students' tendency to respond in a socially desirable fashion. Moreover, our path analysis showed that once performance-approach goals are assessed as pure aims, they did not emerge as significant predictors of learning strategies (despite their positive bivariate intercorrelation) when mastery-approach and performance-avoidance goals were also taken into account. This means that pursuing the goal of outperforming others may not be helpful for an elementary school student to engage in effective learning. Likewise, path analysis revealed a lack of unique relation between performance-avoidance goals and learning strategies (despite their bivariate intercorrelation). This finding indicates that students' goal to avoid doing worse than others does not promote effective learning, although it is not detrimental for learning either, at least in the present research. Although recent research has similarly shown no relation between performance-avoidance goals and learning strategies (e.g., Phan, 2009), future research needs to verify our findings as the majority of

Table 2

Bivariate correlations of the measured variables of the study $(\mathrm{N}=189)$.

\begin{tabular}{|c|c|c|c|c|c|c|c|c|c|c|c|c|}
\hline Variables & 1 & 2 & 3 & 4 & 5 & 6 & 7 & 8 & 9 & 10 & 11 & 12 \\
\hline \multicolumn{13}{|l|}{ Antecedents } \\
\hline 1. Social desirability & - & & & & & & & & & & & \\
\hline 2. Need for achievement & $.14^{*}$ & - & & & & & & & & & & \\
\hline 3. Fear of failure & $-.33^{* *}$ & $.17^{*}$ & - & & & & & & & & & \\
\hline \multicolumn{13}{|l|}{ Achievement goals } \\
\hline 4. Mastery-approach & $.29^{* *}$ & $.30^{* *}$ & .04 & - & & & & & & & & \\
\hline 5. Performance-approach goals & .07 & $.29^{* *}$ & $.25^{* *}$ & $.21^{* *}$ & - & & & & & & & \\
\hline 6. Performance-avoidance goals & -.01 & $.22^{* *}$ & $.22^{* *}$ & $.31^{* *}$ & $.44^{* *}$ & - & & & & & & \\
\hline \multicolumn{13}{|l|}{ Perceived goal structures (GS) } \\
\hline 7. Mastery GS & $.32^{* *}$ & $.29^{* *}$ & .10 & $.27^{* *}$ & $.27^{* *}$ & $.18^{*}$ & - & & & & & \\
\hline 8. Performance-approach GS & -.14 & $.16^{*}$ & $.32^{* *}$ & .09 & $.40^{* *}$ & $.22^{* *}$ & -.02 & - & & & & \\
\hline \multicolumn{13}{|l|}{ Motivational correlates } \\
\hline 9. Critical thinking & $.30^{* *}$ & $.41^{* *}$ & .00 & $.22^{* *}$ & $.31^{* *}$ & .14 & $.35^{* *}$ & .04 & - & & & \\
\hline 10. Metacognitive self-regulation & $.25^{* *}$ & $.50^{* *}$ & .13 & $.28^{* *}$ & $.19^{* *}$ & $.20^{* *}$ & $.39^{* *}$ & .09 & $.41^{* *}$ & - & & \\
\hline 11. Effort regulation & $.35^{* *}$ & $.35^{* *}$ & .00 & $.37^{* *}$ & $.25^{* *}$ & $.18^{*}$ & $.27^{* *}$ & .11 & $.27^{* *}$ & $.45^{* *}$ & - & \\
\hline 12. Learning strategies (aggregate) & $.39^{* *}$ & $.56^{* *}$ & .05 & $.37^{* *}$ & $.33^{* *}$ & $.23^{* *}$ & $.45^{* *}$ & .10 & $.78^{* *}$ & $.81^{* *}$ & $.70^{* *}$ & - \\
\hline
\end{tabular}

$* p<.05$

$* * p<.01$. 


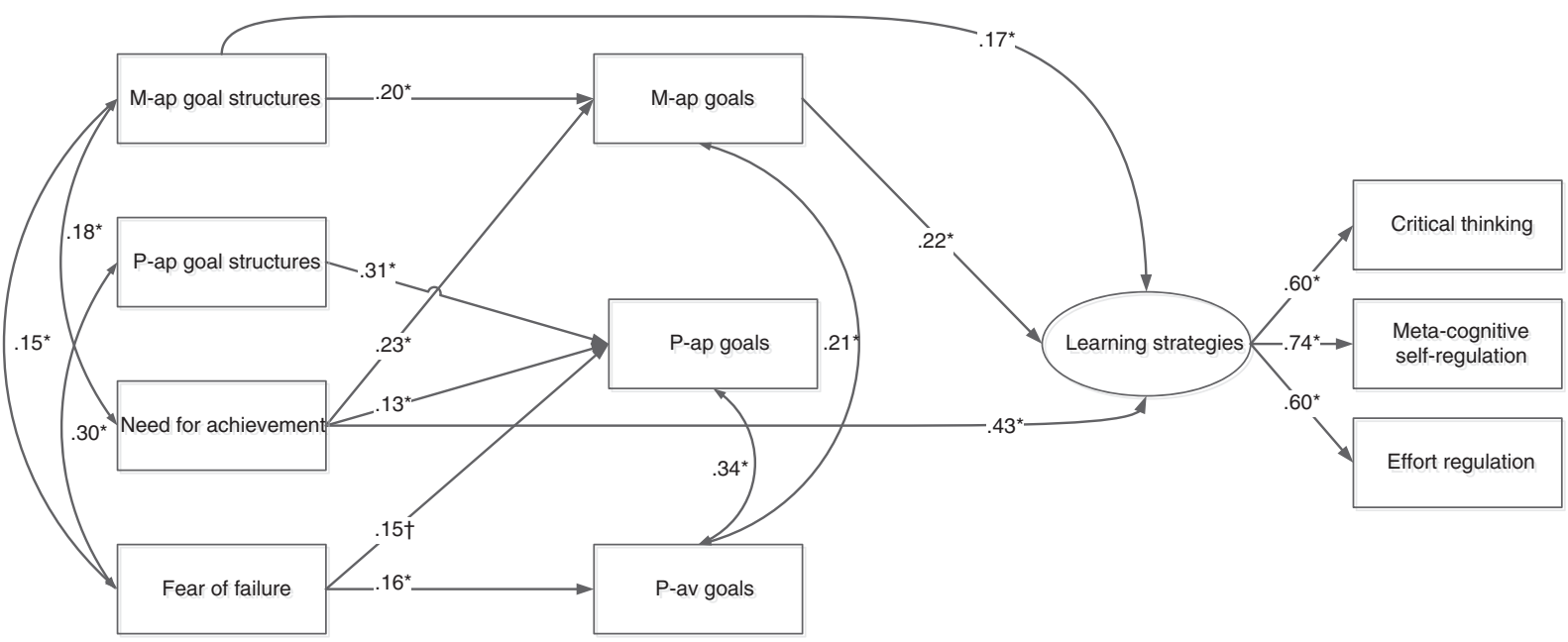

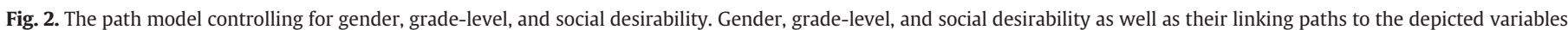
are not shown for the sake of clarity. All the paths are standardized. Note. $\dagger p=.05$. ${ }^{*} p<.05$.

studies have underscored the negative effects of performanceavoidance goals on learning strategies (Senko et al., 2008). Additionally, future studies that will undertake person-centered analyses may shed more light about which combination of goals (e.g., high mastery-approach and low performance-avoidance) constitutes the most adaptive motivational profile.

\subsection{The explanatory role of achievement goals}

Although the extant literature has provided sufficient evidence of the positive relation of mastery goals and mastery goal structures to desired motivational outcomes (Midgley, 2002), the present study extends our knowledge on this issue because it also considered achievement motives as distal predictors of learning strategies. Having concurrently considered personal and contextual antecedents of achievement goals, we found mastery-approach goals to partially mediate the relation between antecedents of achievement goals and learning strategies. Consistent with our hypothesis, we found that the need for achievement was positively related both directly and indirectly (through mastery-approach goals) to learning strategies over and above the relations of perceived mastery goal structures to these motivational outcomes. As our findings suggest, elementary school students who tend to approach an achievement situation to attain success, are more likely to endorse mastery-approach goals and to exhibit critical thinking, metacognitive strategies, and effort regulation. Broadly speaking, need for achievement can be understood as an optimal motivational force that facilitates the adoption of the most adaptive achievement goal (i.e., mastery-approach goals) and self-regulated learning (Bartels \& Magun-Jackson, 2009). This means that a stronger acquired disposition of need for achievement - through positive achievement-related experiences in early childhood (Atkinson, 1957) - could lead to a stronger endorsement of mastery-approach goals and effective learning strategies.

Contrary to our hypothesis, we found no relation (neither direct nor indirect) between fear of failure and learning strategies. A possible explanation could be the age of the participants. Previous research that has provided evidence for the negative relation between fear of failure and learning strategies, has recruited middle school and university students (e.g., Elliot \& Murayama, 2008). Therefore, further investigation of the relation of fear of failure with learning strategies to elementary students is needed.

Notably also, perceived mastery goal structures emerged as significant positive predictors of motivational outcomes as they accounted for unique variance in both mastery-approach goals and effective learning strategies. This finding is consistent with previous reports (Murayama \& Elliot, 2009, Wolters, 2004) and shows that even when achievement goals are conceived as pure aims, mastery-approach goals and perceived mastery goal structures are more reliable positive correlates of desired motivational outcomes compared to performance goals and performance-approach goal structures. Obviously, this finding highlights the important role of teachers as they can have a strong influence on the class environment through their teaching practices (Kaplan, Gheen, \& Midgley, 2002). Apparently, teachers are more likely to promote students' metacognitive regulation, effort regulation, and critical thinking when they promote mastery strivings and selfenhancement. Thus, similar to previous findings (e.g., Linnenbrink, 2005; Murayama \& Elliot, 2009), it appears that students' adaptive responses depends, among others, on teachers' instructional practices that emphasize goals focusing on mastery, self-improvement, and learning (Meece, Anderman, \& Anderman, 2006).

In addition, our study contributes to the understanding of the interplay between motivational constructs and outcomes as it takes under consideration students' tendency to give a social desirable response. As the positive correlations between social desirability and desired motivational processes (i.e., mastery-approach goals and perceived mastery goal structures) and outcomes (i.e., effective learning strategies) imply, elementary school students may tend to respond in a social desirable fashion possibly because of their tendency to attribute to themselves and to their social environment some desirable characteristics (Bradley \& Newhouse, 1968). In this regard, it is advisable to account for the socially desirable response-an issue that is often neglected (Thompson \& Phua, 2005). Notably, even after taking into account students' social desirability tendency, the present research substantiates previous findings as it shows that mastery-approach goals in conjunction with need for achievement and mastery classroom environments are positively associated with positive outcomes.

Our study revealed also some gender differences, with females reporting higher levels of need for achievement and fear of failure than males possibly because as girls exhibit higher level of emotional awareness (Bajgar, Ciarrochi, Lane, \& Deane, 2005) they may be more assertive when reporting their need for achievement and fear of failure. Additionally, our study showed, similar to that reported by KenneyBenson, Pomerantz, Ryan, and Patrick (2006) that females reported higher level of effective learning strategies and that compared to fifth-grade students, their sixth-grade counterparts showed less preference for performance goals. Assuming that older students deal with more difficult school-related activities, it makes sense to hypothesize that older students are less likely to endorse performance goals as recent research has shown that increases in task difficulty coincide with decreases in the endorsement of performance goals (Kumar \& Jagacinski, 2011). 


\section{Limitation}

Our study contains several limitations that should be mentioned. First, because our research design is correlational no inference about causality can be deduced. Assuming that youngsters' personality dispositions such as need for achievement and fear of failure are more malleable, it is equally possible that elementary students who are accustomed to recruit more adaptive learning strategies are more oriented toward success, endorse more fervently mastery-approach goals, and perceive that their classroom environment focuses on improvement and understanding. Most likely, a reciprocal relationship exists and more research with experimental or long-term longitudinal designs is needed to examine the causal relationships among personal dispositions, perceived goal structures, achievement goals, and learning strategies. Second, our sample was relatively small. Third, the internal consistency of some of the used scales was marginal. Fourth, the nested structure of the data may imply a classroom effect which could not be analyzed due to the small number of higher-order units (i.e., classrooms; Maas \& Hox, 2005). Obviously, the teacher or the classroom climate could have an impact on the observed relationships. Unfortunately however, in our study we were unable to consider such classroom effects and future research could address this issue. Finally, the tested relations were examined in one single age group and one single culture and therefore, more studies should be conducted before the present findings can be generalized to other age groups and cultures.

\section{Conclusion}

The hierarchical model provides a useful framework for understanding elementary school students' motivational functioning in an achievement situation. A simultaneous consideration of personal and contextual antecedents of achievement goals reveals the important role of an appetitive form of disposition (i.e., need for achievement) in conjunction with a classroom environment which focus on mastery strivings and self-improvement as they both were directly and indirectly, that is, through mastery-approach goals, associated to learning strategies.

\section{References}

Ames, C. (1992). Classrooms: Goals, structures, and student motivation. Journal of Educational Psychology, 84, 261-271, http://dx.doi.org/10.1037//0022-0663.84.3.261.

Atkinson, J. W. (1957). Motivational determinants of risk-taking behavior. Psychology Review, 64, 359-372, http://dx.doi.org/10.1037/h0043445.

Bajgar, J., Ciarrochi, J., Lane, R., \& Deane, F. P. (2005). Development of the levels of emotional awareness scale for children. British Journal of Developmental Psychology, 23 569-586, http://dx.doi.org/10.1348/026151005X35417.

Bartels, J. M., \& Magun-Jackson, S. (2009). Approach-avoidance motivation and metacognitive self-regulation: The role of need for achievement and fear of failure. Learning and Individual Differences, 19, 459-463, http://dx.doi.org/10.1016/ j.lindif.2009.03.008

Bjørnebekk, G., \& Diseth, Å. (2010). Approach and avoidance temperaments and achievement goals among children. Personality and Individual Differences, 49, 938-943, http://dx.doi.org/10.1016/j.paid.2010.07.034.

Bong, M. (2009). Age-related differences in achievement goal differentiation. Journal of Educational Psychology, 101, 879-896, http://dx.doi.org/10.1037/a0015945.

Bradley, F. O., \& Newhouse, R. C. (1968). Sociometric choice and self-perception of upper elementary school children. American Educational Research Journal, 5, 708-711.

Ciani, K. D., \& Sheldon, K. M. (2010). Evaluating the mastery-avoidance construct: A study of elite college baseball players. Psychology of Sport and Exercise, 11, 127-132.

Chen, L. H., Wu, C., Kee, Y. H., Lin, M., \& Shui, S. (2009). Fear of failure, $2 \times 2$ achievement goal and self-handicapping: An examination of the hierarchical model of achievement motivation in physical education. Contemporary Educational Psychology, 34 298-305, http://dx.doi.org/10.1016/j.cedpsych.2009.06.006.

Church, M. A., Elliot, A. J., \& Gable, S. L. (2001). Perceptions of classroom environment achievement goals, and achievement outcomes. Journal of Educational Psychology, 93, 43-54, http://dx.doi.org/10.1037//0022-0663.93.1.43.

Conroy, D. E. (2001). Progress in the development of a multidimensional measure of fear of failure: The performance failure appraisal inventory (PFAI). Anxiety, Stress, and Coping, 14, 431-452, http://dx.doi.org/10.1080/10615800108248365.
Darnon, C., Dompnier, B., Delmas, F., Pulfrey, C., \& Butera, F. (2009). Achievement goal promotion at university: Social desirability and social utility of mastery and performance goals. Journal of Personality and Social Psychology, 96, 119-134, http://dx.doi.org/10. $1037 / \mathrm{a} 0012824$.

Diseth, Å., \& Kobbeltvedt, T. (2010). A mediation analysis of achievement motives, goals, learning strategies, and academic achievement. British Journal of Educational Psychology, 80, 671-687, http://dx.doi.org/10.1348/000709910X492432.

Dweck, C. \& Leggett, E. (1988). A social-cognitive approach to motivation and personality. Psychology Review, 95, 256-273, http://dx.doi.org/10.1037//0033-295X.95.2.256.

Elliot, A. J. (1999). Approach and avoidance motivation and achievement goals. Educational Psychologist, 34, 169-189, http://dx.doi.org/10.1207/s15326985ep3403_3.

Elliot, A. J. (2005). A conceptual history of the achievement goal construct. In A. J. Elliot, \& C. Dweck (Eds.), Handbook of competence and motivation (pp. 52-72). New York: Guilford Press.

Elliot, A. J., \& Church, M. A. (1997). A hierarchical model of approach and avoidance achievement motivation. Journal of Personality and Social Psychology, 72, 218-232, http://dx.doi.org/10.1037//0022-3514.72.1.218.

Elliot, A. J., \& Harackiewicz, J. M. (1996). Approach and avoidance achievement goals and intrinsic motivation: A mediational analysis. Journal of Personality and Social Psychology, 70, 461-475, http://dx.doi.org/10.1037/0022-3514.70.3.461.

Elliot, A. J., \& McGregor, H. A. (2001). A $2 \times 2$ achievement goal framework. Journal of Personality and Social Psychology, 80, 501-519, http://dx.doi.org/10.1016/j. psychsport.2005.08.012.

Elliot, A. J., \& Moller, A. C. (2003). Performance-approach goals: Good of bad form of regulation? International Journal of Educational Research, 39, 339-356, http://dx.doi.org/10. 1016/j.ijer.2004.06.003.

Elliot, A. J., \& Murayama, K. (2008). On the measurement of achievement goals: Critique, illustration, and application. Journal of Educational Psychology, 100, 613-628, http://dx.doi.org/10.1037/0022-0663.100.3.613.

Hambleton, R. K. (1994). Guidelines for adapting educational and psychological tests: A progress report. European Journal of Psychological Assessment, 10, 229-240.

Harackiewicz, J. M., Durik, A. M., Barron, K. E., Linnenbrink-Garcia, L., \& Tauer, J. M. (2008). The role of achievement goals in the development of interest: Reciprocal relations between achievement goals, interest and performance. Journal of Educational Psychology, 100, 105-122, http://dx.doi.org/10.1037/0022-0663.100.1.105.

Hulleman, C. S., Schrager, S. M., Bodmann, S. M., \& Harackiewicz, J. M. (2010). A meta-analytic review of achievement goal measures: Different labels for the same constructs or different constructs with similar labels? Psychological Bulletin, 136, 422-449, http://dx.doi.org/10.1037/0022-0663.100.2.398.

Kaplan, A., Gheen, M., \& Midgley, C. (2002). Classroom goal structure and student disruptive behavior. British Journal of Educational Psychology, 72, 191-211, http://dx.doi.org/10.1348/000709902158847.

Kenney-Benson, G. A., Pomerantz, E. M. Ryan, A. M. \& Patrick, H. (2006). Sex differences in math performance: The role of children's approach to schoolwork. Developmental Psychology, 42, 11-26, http://dx.doi.org/10.1037/0012-1649.42.1.11.

Kumar, S., \& Jagacinski, C. M. (2011). Confronting task difficulty in ego involvement: Change in performance goals. Journal of Educational Psychology, 103, 664-682, http://dx.doi.org/10.1037/a0023336.

Lang, G. W. B., \& Fries, S. (2006). A revised 10-item version of the achievement motives scale. European Journal of Psychological Assessment, 22, 216-224, http://dx.doi.org/10. 1027/1015-5759.22.3.216

Lau, S., \& Nie, Y. (2008). Interplay between personal goals and classroom goal structures in predicting students outcomes: A multilevel analysis of person-context interactions. Journal of Educational Psychology, 100,15-29, http://dx.doi.org/10.1037/ 0022-0663.100.1.15.

Linnenbrink, E. A. (2005). The dilemma of performance-approach goals: The use of multiple goal contexts to promote students' motivation and learning. Journal of Educational Psychology, 97, 197-213, http://dx.doi.org/10.1037/0022-0663.97.2.197.

Maas, C. J. M., \& Hox, J. J. (2005). Sufficient sample sizes for multilevel modeling. Methodology, 1, 85-91, http://dx.doi.org/10.1027/1614-1881.1.3.85.

Maehr, M. L., \& Midgley, C. (1996). Transforming school cultures. Boulder, CO: Westview Press.

Meece, J. L., Anderman, E. M., \& Anderman, L. H. (2006). Classroom goal structure, achievement motivation, and academic achievement. Annual Review of Psychology, 57, 487-503, http://dx.doi.org/10.1146/annurev.psych.56.091103.070258.

Metallidou, P., \& Vlachou, A. (2010). Children's self-regulated learning profile in language and mathematics: The role of task value beliefs. Psychology in the Schools, 47, 776-778, http://dx.doi.org/10.1002/pits.20503.

Midgley, C. (Ed.). (2002). Goals, goal structures and patterns of adaptive learning. Mahwah, NJ: Lawrence Erlbaum.

Midgley, C., Maehr, M. L., Hruda, L. Z., Anderman, E., Anderman, L., Freeman, K. E., Gheen, M., Kaplan, A., Kumar, R., Middleton, M. J., Nelson, J., Roeser, R., \& Urdan, T. (2000). Manual for the Patterns of Adaptive Learning Scales (PALS). Ann Arbor, MI: University of Michigan.

Miki, K., \& Yamauchi, H. (2005). Perceptions of classroom goal structures, personal achievement goal orientations, and learning strategies. Japanese Journal of Psychology, $76,260-268$

Murayama, K., \& Elliot, A. J. (2009). The joint influence of personal achievement goals and classroom goal structures on achievement relevant-outcomes. Journal of Educational Psychology, 101, 432-447, http://dx.doi.org/10.1037/a0014221.

Phan, H. P. (2009). Amalgamation of future time orientation, epistemological beliefs, achievement goals and study strategies: Empirical evidence established. British Journal of Educational Psychology, 79, 155-173, http://dx.doi.org/10.1348/ $000709908 \times 306864$

Pintrich, P. R. (2000). An achievement goal theory perspective on issues in motivation terminology, theory, and research. Contemporary Educational Psychology, 25, 92-104, http://dx.doi.org/10.1006/ceps.1999.1017. 
Pintrich, R. R., \& De Groot, E. V. (1990). Motivational and self-regulated learning components of classroom academic performance. Journal of Educational Psychology, 82, 33-40, http://dx.doi.org/10.1037/0022-0663.82.1.33.

Senko, C., Durik, A. M., \& Harackiewicz, J. M. (2008). Historical perspectives and new directions in achievement goal theory: Understanding the effects of mastery and performance-approach goals. In J. Y. Shah, \& W. S. Gardner (Eds.), Handbook of motivation science (pp. 100-113). Guilford Press: New York.

Tapola, A., \& Niemivirta, M. (2008). The role of achievement goal orientations in students' perceptions of and preferences for classroom environment. British Journal of Educational Psychology, 78, 291-312, http://dx.doi.org/10.1348/000709907X205272.

Thompson, E. R., \& Phua, F. T. T. (2005). Reliability among senior managers of the MarloweCrowne short-form social desirability scale. Journal of Business and Psychology, 19, 541-554, http://dx.doi.org/10.1007/s10869-005-4524-4.
Urdan, T. (2004). Predictors of academic self-handicapping and achievement: Examining achievement goals, classroom goal structures and culture. Journal of Educational Psychology, 96, 251-264, http://dx.doi.org/10.1037/0022-0663.96.2.251.

Weinstein, C. E., \& Mayer, R. F. (1986). The teaching of learning strategies. In M. C. Wittrock (Ed.), Handbook of research on teaching (pp. 315-327). (3rd ed.). New York: Macmillan.

Wolters, C. A. (2004). Advancing achievement goal theory: Using goal structures and goal orientations to predict students' motivation, cognition and achievement. Journal of Educational Psychology, 96, 236-250, http://dx.doi.org/10.1037/0022-0663.96.2.236. 